\title{
Limited spread of a rare spike E484K-harboring SARS-CoV-2 in Marseille, France
}

\author{
Philippe Colson ${ }^{1,2}$ (D) Jacques Fantini ${ }^{3} \cdot$ Nouara Yahi $^{3} \cdot$ Jeremy Delerce ${ }^{1} \cdot$ Anthony Levasseur $^{1,2}$. \\ Pierre-Edouard Fournier ${ }^{1,2}$. Jean-Christophe Lagier ${ }^{1,2}$. Didier Raoult ${ }^{1,2} \cdot$ Bernard La Scola $^{1,2}$
}

Received: 21 July 2021 / Accepted: 5 November 2021 / Published online: 27 January 2022

(c) The Author(s), under exclusive licence to Springer-Verlag GmbH Austria, part of Springer Nature 2021

\begin{abstract}
We detected SARS-CoV-2 of PANGO lineage R. 1 with the spike substitution E484K in three patients. Eleven other sequences in France and 8,831 worldwide were available from GISAID, 92\% originating from Japan. The three genome sequences from our institute were phylogenetically closest to another from Guinea-Conakry, where one of the patients had travelled. These viruses did not exhibit any unusual features in cell culture. Spike structural predictions indicated a 1.3-time higher transmissibility index than for the globally spread B.1.1.7 variant but also an affinity loss for gangliosides that might have slowed dissemination. The spread of new SARS-CoV-2 mutants/variants is still not well understood and therefore difficult to predict, and this hinders implementation of effective preventive measures, including adapted vaccines.
\end{abstract}

The diversity of SARS-CoV-2 has expanded considerably since the first detection of this virus in December 2019 in China. Several new SARS-CoV-2 variants and mutants have been classified as variants of concern regarding their transmissibility, pathogenicity, and potential to escape immune responses elicited by infection or vaccination [1,2]. These include viruses of PANGO lineages B.1.351 (WHO Beta variant) and B.1.1.28/P.1 (Gamma variant) that have spread worldwide, as well as the less-prevalent lineages B.1.525 (Eta variant) and B.1.1.345, all of which harbor the substitution E484K in their spike protein [3-5]. This substitution, located in the receptor-binding domain (RBD) of the spike, has been reported to decrease sensitivity to neutralizing monoclonal antibodies and convalescent plasma in several studies [5-8]. Here, we describe three infections with

Handling Editor: William G. Dundon.

Philippe Colson

philippe.colson@univ-amu.fr

1 IHU Méditerranée Infection, 19-21 boulevard Jean Moulin, 13005 Marseille, France

2 Aix-Marseille Univ., Institut de Recherche pour le Développement (IRD), Assistance Publique-Hôpitaux de Marseille (AP-HM), MEPHI, 27 boulevard Jean Moulin, 13005 Marseille, France

3 Aix-Marseille Univ., INSERM U_1072, 13015 Marseille, France rare E484K-harboring SARS-CoV-2 containing three other amino acid substitutions in the spike, including W152L, which is located in the N-terminal domain (NTD) and possibly reduces sensitivity to neutralizing antibodies [9], and D614G and G679V, located in the S2 subunit. Mutations causing 10 additional amino acid substitutions were found in these three genomes, including six located in the nucleocapsid, one in the membrane protein, one in the nsp12 gene product (RNA-dependent RNA polymerase), one in the nsp13 gene product (RNA helicase), and one in the nsp14 gene product (3'-5' exonuclease) (Fig. 1A).

We classified SARS-CoV-2 from these three patients as Marseille-484K.V1 according to the nomenclature we have implemented locally to facilitate monitoring and analysis of the epidemic. They were also classified into GISAID [10] clade GR, Nextstrain clade 20B [11], and PANGO lineage R.1 [12]. The three Marseille-484K.V1 genome sequences were obtained at our institute from respiratory samples collected between February 11 and April 19, 2021. They accounted for $0.04 \%$ of the 8,417 SARS-CoV-2 sequences we had deposited in GISAID as of June 17, 2021. As of this date, 8,831 sequences of the PANGO lineage R.1 were available from the GISAID database (https://www.gisaid. org/) [10]. They were obtained from patients sampled between February 1, 2020, and May 28, 2021, but only four sequences were from samples collected before October 24, 2020 (Fig. 1B). The 8,831 sequences originated from 34 countries on five continents, but $99 \%$ originated from 13 
A

SARS-CoV-2 genome

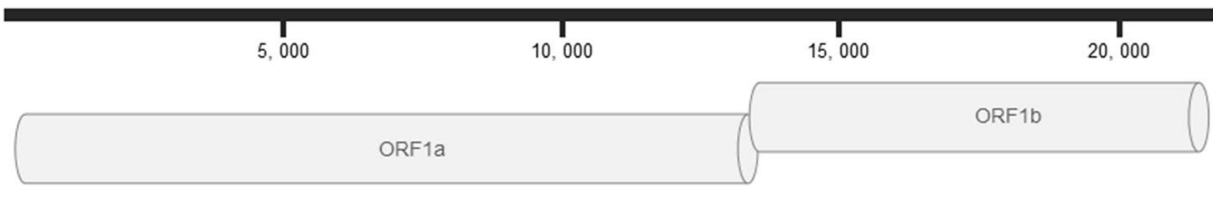

Non-structural proteins
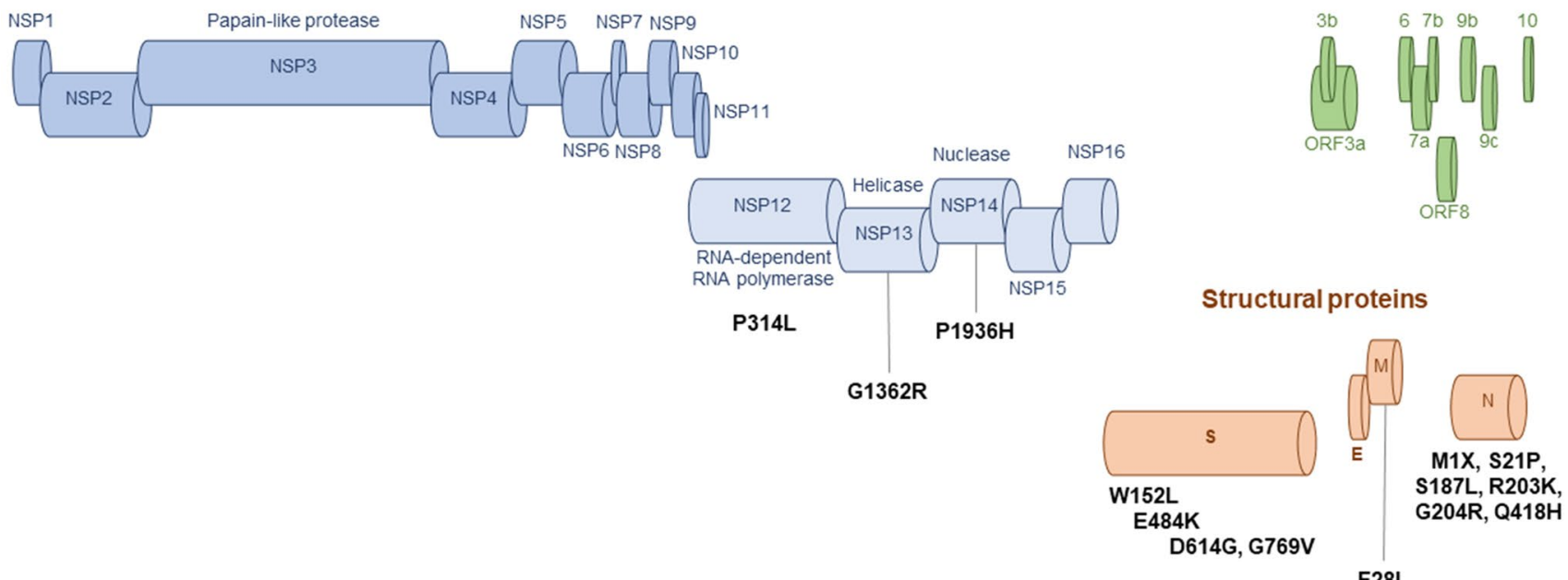

B

250

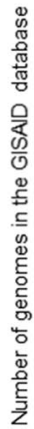

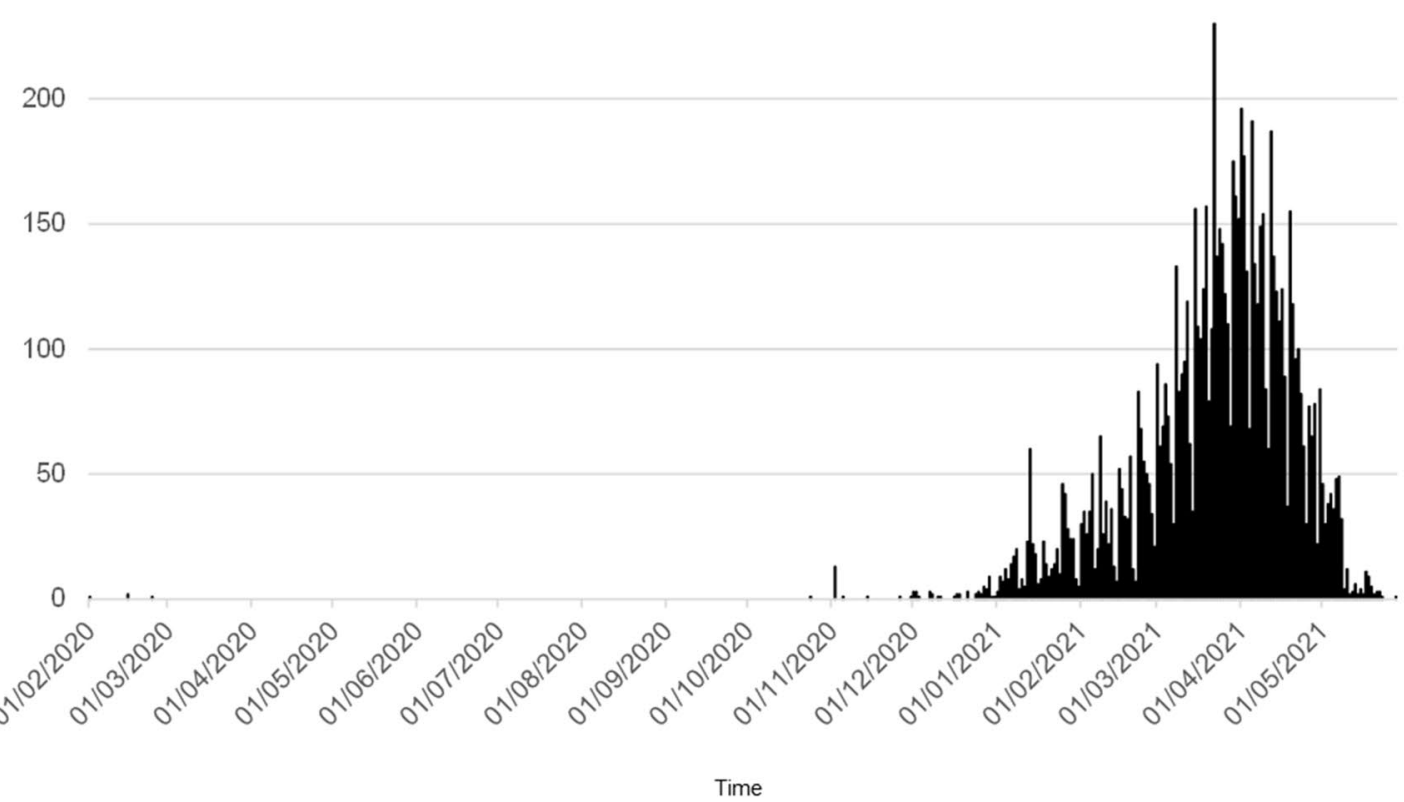

Fig. 1 Map of the SARS-CoV-2 genome (A) and number of were obtained from the GISAID database (https://www.gisaid.org/) sequences classified in PANGO lineage R.1 in the GISAID database [10] on June 17, 2021. 
countries, and $92 \%$ originated from Japan $(5,890$ sequences, $67 \%)$ or the USA (2,250 sequences, $26 \%$ ). In Japan, all but four sequences were obtained from samples collected between November 30, 2020, and May 17, 2021 [13, 14]. This SARS-CoV-2 lineage was also associated with 46 cases in skilled-nursing facilities in March 2021 in Kentucky, USA [15]. In this outbreak, the efficacy of immunization with the BioNTech mRNA vaccine against SARS-CoV-2 infection was estimated to be $66 \%$ and $76 \%$ among the residents and vaccinated health-care personnel, respectively, and four reinfections (two laboratory-confirmed infections separated by $>90$ days) were reported, including one in a resident who eventually died. In France, only 11 other cases were detected, and together with our three genome sequences, they accounted for $0.03 \%$ of the 48,137 sequences deposited in the GISAID database as of June 17, 2021.

Phylogenetic analysis of the three Marseille-484K.V1 sequences obtained at our institute showed that they clustered (bootstrap value, $80 \%$ ) with a genome sequence originating from Guinea-Conakry that was the best BLAST hit in the GISAID database [10] (Fig. 2). The three patients were women between 24 and 55 years old. One of them reported that she had returned from a trip to Guinea-Conakry. None of the three patients were hospitalized. Cell culture isolation was performed as described previously [16] by inoculating the respiratory samples from two of the three patients onto Vero E6 cells. The cycle threshold values of qPCR were 15 and 20 for the two inoculated samples. A cytopathic effect was observed after 5 days during the first passage, and no particular phenotypic features were noted, including when compared to viruses isolated during the period of MarchApril 2020 [16].

Structural analysis of the Marseille-484K.V1 spike protein showed that amino acid substitutions G679V and D614G are at the same height in the spike protein, in a region considered to play a role in the conformational change required for demasking the RBD in the open state of the trimeric spike (Fig. 3A). Interestingly, the surface potential of the RBD was markedly increased by substitution E484K (Fig. 3B), suggesting a kinetic advantage for this virus for accessing the electronegative surface of the ACE-2 receptor. The electrostatic surface potential of the NTD was also increased by the mutation W152L, but by an indirect mechanism of compaction of the domain that decreases the electronegative areas in favor of an enlarged electropositive surface. Although these changes in the surface potential of the RBD and the NTD may potentiate the attraction of the viral envelope to lipid rafts containing ACE-2 [17], this kinetic advantage appeared to be tempered by a concomitant loss of affinity of the RBD for ACE-2 $(\Delta \mathrm{Gmut} / \Delta \mathrm{Gwt}=0.93)$ and of the NTD for lipid raft gangliosides $(\Delta \mathrm{Gmut} / \Delta \mathrm{Gwt}=0.90)$.
Together with surface potential measurements of RBD and NTD surfaces, these affinity estimations obtained by molecular modeling approaches were used to calculate the transmissibility index (T-index) of Marseille-484K.V1 according to our published protocol [18]. The T-index was 4.53, which is twice the T-index of the Wuhan-Hu-1 virus. In comparison, the T-index of the globally spread B.1.1.7 variant (a.k.a. Alpha variant) is 3.59, suggesting that Marseille-484K. V1 viruses could have been expected to disseminate more widely than observed. However, the loss of affinity of the W152L mutant for gangliosides is not anecdotical. Indeed, the large flat surface of the ganglioside-binding domain of the NTD [19] has a better geometric complementarity in the Wuhan B.1 strain than in the Marseille-484K.V1 viruses, as illustrated in Figure 3C. This may have contributed to slowing the dissemination of these Marseille-484K.V1 viruses. However, immune neutralization and other host factors may also explain why they did not outcompete other SARSCoV-2 strains that circulated concomitantly.

The Marseille-484K.V1, or R.1, lineage is another example of convergent evolution leading to the amino acid substitution $\mathrm{E} 484 \mathrm{~K}$, as also observed for the substitutions L452R [20], N501Y [21], Q677H [22], and L18F [23], which have occurred independently in various SARS-CoV-2 lineages and geographical areas. The low level of circulation of this variant in France and worldwide, with the notable exceptions of Japan and the USA, contrasts with the dramatic spread of other E484K-harboring viruses such as lineages B.1.351 and B.1.1.28/P.1. Viral culture did not reveal particularities, while structural analysis of the spike protein provided some hints to explain the seemingly low transmissibility of this variant. Although there is currently more information about the link between amino acid substitutions in the spike protein and viral replicative capacity, transmissibility, and immune escape [1], other mutations located in the Nsp13, Nsp14, M, and $\mathrm{N}$ genes of this Marseille-484K.V1 variant might also affect its replicative capacity and transmissibility. The Nsp13 product has both helicase and RNA 5'-triphosphatase activities and is essential for viral replication [24]. It has been reported to interact with the RNA-dependent RNA polymerase and acts in partnership with the replication-transcription complex. The Nsp14 product is a dual-functional enzymatic protein with 3'-to-5' exonuclease activity that is responsible for the SARS-CoV-2 RNA proofreading activity, and with guanine-N7 methyltransferase activity allowing methylation of the viral mRNA cap structure [25]. The membrane protein is the most abundant structural protein in the SARS-CoV-2 virion and has been reported to be involved in several functions, including attachment to the host cell, protein assembly, and increased glucose transport [26]. Finally, the SARS-CoV-2 nucleocapsid protein 


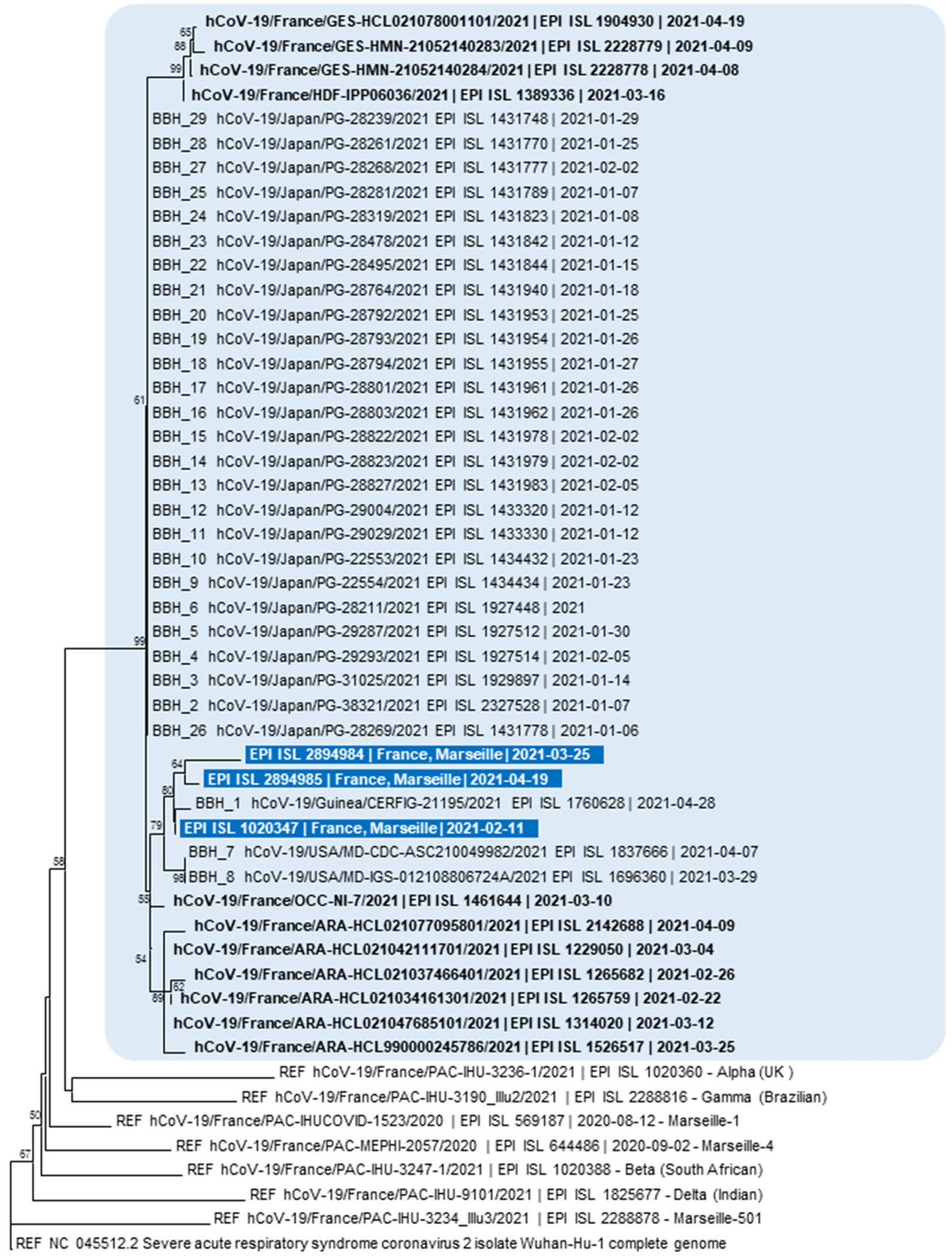

$\stackrel{1}{0.00020}$ 
4Fig. 2 Phylogenetic analysis based on the full-length genome sequences of the three Marseille-484K.V1 viruses and the 30 sequences with the highest BLAST scores obtained from the GISAID database (https://www.gisaid.org/) [10]. These sequences are indicated by "BBH" (for best BLASTn hit) at the beginning of the sequence name. Additional sequences indicated by REF (for reference) at the beginning of the sequence name include the genome sequence of the Wuhan-Hu-1 isolate and genome sequences obtained at our institute and classified as predominant SARS-CoV-2 variants. Nucleotide sequence alignments were performed using MUSCLE software (http://www.ebi.ac.uk/Tools/msa/muscle/). Evolutionary history was inferred using MEGAX software (http://www.megasoftware. net/) using the neighbor-joining method and the Kimura 2-parameter model. The percentage of replicate trees in which the associated taxa clustered together in the bootstrap test $(1,000$ replicates) is shown next to the branches. The tree is drawn to scale, with branch lengths in the same units as those of the evolutionary distances used to infer the phylogenetic tree; the scale bars indicate the number of nucleotide substitutions per site. Bootstrap values $>50 \%$ are indicated on the tree.

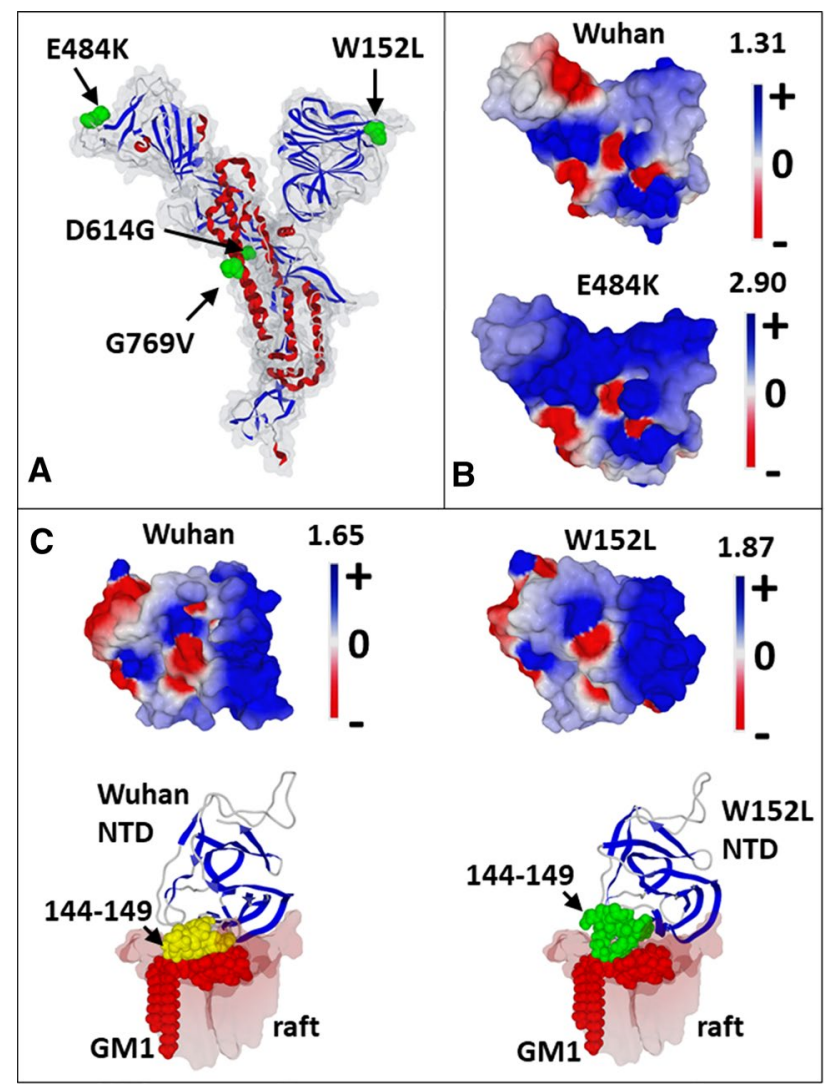

Fig. 3 Structural analysis of the Marseille-484K.V1 virus. (A) Localization of mutations by molecular modeling of the variant spike. (B) Effect of the E484K mutation on the electrostatic surface potential of the RBD. The values indicate the estimate of the surface potential of the RBD region facing the host cell membrane, as determined using Molegro Molecular Viewer software. Blue regions are electropositive, red regions are electronegative, and white regions are neutral. (C) Effect of the W152L mutation on the electrostatic surface potential of the NTD (upper panels). Molecular models of B.1 and mutant NTD binding to lipid rafts (GM1 gangliosides) are shown in the lower panels. Region 144-149 of the NTD is indicated in yellow (B.1 NTD) and green (Marseille_184). is critical for ribonucleocapsid formation and has also been implicated in viral genome replication [27]. In addition, one should also consider as a possible explanation for the limited spread of the Marseille-484K.V1 viruses the other SARSCoV-2 that co-circulated with them, such as the predominant Alpha/B.1.1.7 variant, with which they competed.

Taken together, previous findings show that, despite a tremendous number of epidemiological, genomic, proteomic, structural, and cell culture studies carried out on SARS-CoV-2, the emergence, spread, and outcome of new mutants and variants are not well understood and therefore difficult to predict. Notably, this hampers the implementation of the most appropriate preventive measures, including the development of suitable vaccines.

Acknowledgments We are thankful to Clio Grimaldier for her technical help with viral culture.

Author contributions Conceived and designed the experiments: PC, JF, NY, DR, BLS. Contributed materials, data, analysis tools: PC, JF, NY, JD, AL, PEF, JCL, BLS. Analyzed the data: all authors. Wrote the paper: PC, JF. All authors approved the last version of the paper.

Funding This work was supported by the French Government under the "Investments for the Future" program managed by the National Agency for Research (ANR), Méditerranée-Infection 10-IAHU-03 and was also supported by Région Provence Alpes Côte d'Azur and European funding FEDER PRIMMI (Fonds Européen de Développement Régional-Plateformes de Recherche et d'Innovation Mutualisées Méditerranée Infection), FEDER PA 0000320 PRIMMI.

Availability of data and material SARS-CoV-2 genome sequences generated in our institute have been submitted to the GISAID sequence database (https://www.gisaid.org/) [10].

\section{Declarations}

Conflict of interest The authors have no conflicts of interest to declare. Funding sources had no role in the design and conduct of the study, collection, management, analysis, or interpretation of the data or the preparation, review, or approval of the manuscript.

Ethical approval The data were generated as part of the routine work at Assistance Publique-Hôpitaux de Marseille (Marseille University Hospitals). This study was approved by the ethics committee of Hospital University Institute Méditerranée Infection (no. 2020-016-03).

Consent to participate and for publication According to European General Data Protection Regulation No. 2016/679, patients were informed of the potential use of their medical data and that they could refuse the use of their data. The analysis of collected data followed the MR-004 reference methodology registered under No. 2020-151 in the AP-HM register. 


\section{References}

1. Harvey WT, Carabelli AM, Jackson B, Gupta RK, Thomson EC, Harrison EM, Ludden C, Reeve R, Rambaut A, COVID-19 Genomics UK (COG-UK) Consortium, Peacock SJ, Robertson DL (2021) SARS-CoV-2 variants, spike mutations and immune escape. Nat Rev Microbiol 19:409-424

2. Konings F, Perkins MD, Kuhn JH, Pallen MJ, Alm EJ, Archer BN, Barakat A, Bedford T, Bhiman JN, Caly L, Carter LL, Cullinane A, de Oliveira T, Druce J, El Masry I, Evans R, Gao GF, Gorbalenya AE, Hamblion E, Herring BL, Hodcroft E, Holmes EC, Kakkar M, Khare S, Koopmans MPG, Korber B, Leite J, MacCannell D, Marklewitz M, Maurer-Stroh S, Rico JAM, Munster VJ, Neher R, Munnink BO, Pavlin BI, Peiris M, Poon L, Pybus O, Rambaut A, Resende P, Subissi L, Thiel V, Tong S, van der Werf S, von Gottberg A, Ziebuhr J, Van Kerkhove MD (2021) SARS$\mathrm{CoV}-2$ variants of interest and concern naming scheme conducive for global discourse. Nat Microbiol 6:821-823

3. Ferrareze PAG, Franceschi VB, Mayer AM, Caldana GD, Zimerman RA, Thompson CE (2021) E484K as an innovative phylogenetic event for viral evolution: genomic analysis of the E484K spike mutation in SARS-CoV-2 lineages from Brazil. Infect Genet Evol 93:104941

4. Lesho E, Corey B, Lebreton F, Ong AC, Swierczewski BE, Bennett JW, Walsh EE, Mc Gann P (2021) Emergence of the E484K mutation in SARS-CoV-2 lineage B.1.1.345 in upstate New York. Clin Infect Dis. https://doi.org/10.1093/cid/ciab507 (online ahead of print)

5. Gobeil SM, Janowska K, McDowell S, Mansouri K, Parks R, Stalls V, Kopp MF, Manne K, Li D, Wiehe K, Saunders KO, Edwards RJ, Korber B, Haynes BF, Henderson R, Acharya P (2021) Effect of natural mutations of SARS-CoV-2 on spike structure, conformation and antigenicity. Science. https://doi.org/10. 1126/science.abi6226 (online ahead of print)

6. Greaney AJ, Loes AN, Crawford KHD, Starr TN, Malone KD, Chu HY, Bloom JD (2021) Comprehensive mapping of mutations in the SARS-CoV-2 receptor-binding domain that affect recognition by polyclonal human plasma antibodies. Cell Host Microbe 29:463-476

7. Xie X, Liu Y, Liu J, Zhang X, Zou J, Fontes-Garfias CR, Xia H, Swanson KA, Cutler M, Cooper D, Menachery VD, Weaver SC, Dormitzer PR, Shi PY (2021) Neutralization of SARS-CoV-2 spike 69/70 deletion, E484K and N501Y variants by BNT162b2 vaccine-elicited sera. Nat Med 27:620-621

8. Wibmer CK, Ayres F, Hermanus T, Madzivhandila M, Kgagudi P, Oosthuysen B, Lambson BE, de Oliveira T, Vermeulen M, van der Berg K, Rossouw T, Boswell M, Ueckermann V, Meiring S, von Gottberg A, Cohen C, Morris L, Bhiman JN, Moore PL (2021) SARS-CoV-2 501Y.V2 escapes neutralization by South African COVID-19 donor plasma. Nat Med 27:622-625

9. Ip JD, Kok KH, Chan WM, Chu AW, Wu WL, Yip CC, To WK, Tsang OT, Leung WS, Chik TS, Chan KH, Hung IF, Yuen KY, To KK (2020) Intra-host non-synonymous diversity at a neutralizing antibody epitope of SARS-CoV-2 spike protein N-terminal domain. Clin Microbiol Infect. https://doi.org/10.1016/j.cmi.2020. 10.030 (online ahead of print)

10. Shu Y, McCauley J (2017) GISAID: Global initiative on sharing all influenza data - from vision to reality. Euro Surveill 22:30494

11. Hadfield J, Megill C, Bell SM, Huddleston J, Potter B, Callender C, Sagulenko P, Bedford T, Neher RA (2018) Nextstrain: real-time tracking of pathogen evolution. Bioinformatics 34:4121-4123

12. Rambaut A, Holmes EC, O'Toole A, Hill V, McCrone JT, Ruis C, du Plessis L, Pybus OG (2020) A dynamic nomenclature proposal for SARS-CoV-2 lineages to assist genomic epidemiology. Nat Microbiol 5:1403-1407

13. Hirotsu Y, Omata M (2021) Detection of R.1 lineage severe acute respiratory syndrome coronavirus 2 (SARS-CoV-2) with spike protein W152L/E484K/G769V mutations in Japan. PLoS Pathog 17:e1009619

14. Hirotsu Y, Omata M (2021) Household transmission of SARSCoV-2 R.1 lineage with spike E484K mutation in Japan. PLoS Pathog 7:e1009619

15. Cavanaugh AM, Fortier S, Lewis P, Arora V, Johnson M, George K, Tobias J, Lunn S, Miller T, Thoroughman D, Spicer KB (2021) COVID-19 outbreak associated with a SARS-CoV-2 R.1 lineage variant in a skilled nursing Facility after vaccination program-Kentucky, March 2021. MMWR Morb Mortal Wkly Rep 70:639-643

16. Wurtz N, Penant G, Jardot P, Duclos N, La Scola B (2021) Culture of SARS-CoV-2 in a panel of laboratory cell lines, permissivity, and differences in growth profile. Eur J Clin Microbiol Infect Dis 40:477-484

17. Fantini J, Chahinian H, Yahi N (2021) Leveraging coronavirus binding to gangliosides for innovative vaccine and therapeutic strategies against COVID-19. Biochem Biophys Res Commun 538:132-136

18. Fantini J, Yahi N, Azzaz F, Chahinian H (2021) Structural dynamics of SARS-CoV-2 variants: a health monitoring strategy for anticipating Covid-19 outbreaks. J Infect. https://doi.org/10. 1016/j.jinf.2021.06.001 (online ahead of print)

19. Fantini J, Chahinian H, Yahi N (2020) Synergistic antiviral effect of hydroxychloroquine and azithromycin in combination against SARS-CoV-2: What molecular dynamics studies of virus-host interactions reveal. Int J Antimicrob Agents 56:106020

20. Tchesnokova TV, Kulakesara H, Larson L, Bowers V, Rechkina E, Kisiela D, Sledneva Y, Choudhury D, Maslova I, Deng K, Kutumbaka K, Geng H, Fowler C, Greene D, Ralston J, Samadpour M, Sokurenko E (2021) Acquisition of the L452R mutation in the ACE2-binding interface of Spike protein triggers recent massive expansion of SARS-Cov-2 variants. bioRxiv. https://doi.org/10. 1101/2021.02.22.432189

21. Martin DP, Weaver S, Tegally H, San EJ, Shank SD, Wilkinson E, Giandhari J, Naidoo S, Pillay Y, Singh L, Lessells RJ, NGSSA, COVID-19 Genomics UK (COG-UK), Gupta RK, Wertheim JO, Nekturenko A, Murrell B, Harkins GW, Lemey P, MacLean OA, Robertson DL, de Oliveira T, Pond SLK (2021) The emergence and ongoing convergent evolution of the N501Y lineages coincided with a major global shift in the SARS-Cov-2 selective landscape. medRxiv. https://doi.org/10.1101/2021.02.23.21252 268

22. Hodcroft EB, Domman DB, Snyder DJ, Oguntuyo KY, Van Diest M, Densmore KH, Schwalm KC, Femling J, Carroll JL, Scott RS, Whyte MM, Edwards MW, Hull NC, Kevil CG, Vanchiere JA, Lee B, Dinwiddie DL, Cooper VS, Kamil JP (2021) Emergence in late 2020 of multiple lineages of SARS-CoV-2 Spike protein variants affecting amino acid position 677. medRxiv. https://doi.org/10. 1101/2021.02.12.21251658

23. Grabowski F, Kochanczyk M, Lipniacki T (2021) L18F substrain of SARS-CoV-2 VOC-202012/01 is rapidly spreading in England. medRxiv. https://doi.org/10.1101/2021.02.07.21251262

24. Newman JA, Douangamath A, Yadzani S, Yosaatmadja Y, Aimon A, Brandão-Neto J, Dunnett L, Gorrie-Stone T, Skyner R, Fearon D, Schapira M, von Delft F, Gileadi O (2021) Structure, mechanism and crystallographic fragment screening of the SARS-CoV-2 NSP13 helicase. Nat Commun 12:4848 
25. Obermeyer F, Schaffner SF, Jankowiak M, Barkas N, Pyle JD, Park DJ, MacInnis BL, Luban J, Sabeti PC, Lemieux JE (2021) Analysis of 2.1 million SARS-CoV-2 genomes identifies mutations associated with transmissibility. medRxiv. https://doi.org/ 10.1101/2021.09.07.21263228

26. Shen L, Bard JD, Triche TJ, Judkins AR, Biegel JA, Gai X (2021) Emerging variants of concern in SARS-CoV-2 membrane protein: a highly conserved target with potential pathological and therapeutic implications. Emerg Microbes Infect 10:885-893
27. Zheng X, Sun Z, Yu L, Shi D, Zhu M, Yao H, Li L (2021) Interactome analysis of the nucleocapsid protein of SARS-CoV-2 virus. Pathogens 10:1155

Publisher's Note Springer Nature remains neutral with regard to jurisdictional claims in published maps and institutional affiliations. 